
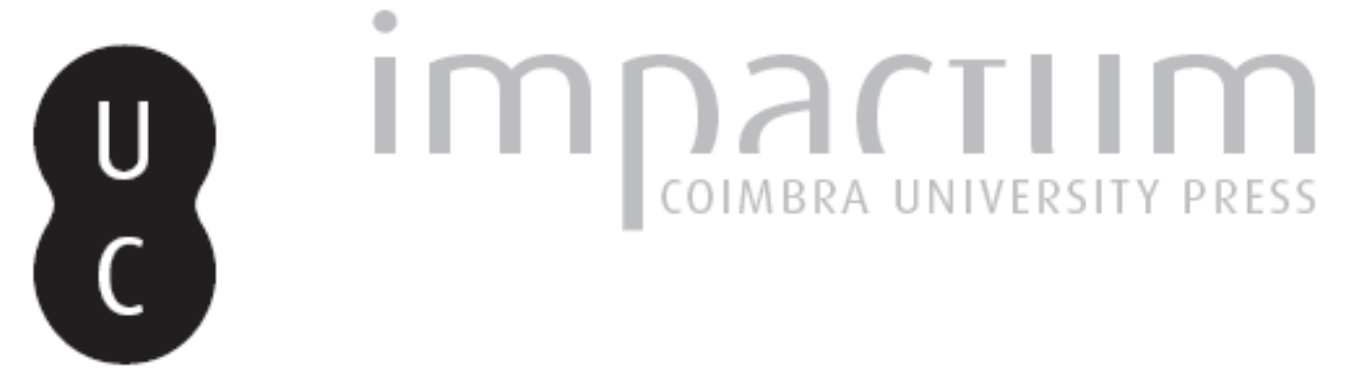

\title{
Eugénio de Castro entre Simbolismo e Futurismo
}

\author{
Autor(es): $\quad$ Marnoto, Rita
}

Publicado por: Faculdade de Letras da Universidade de Coimbra

URL persistente:

URI:http://hdl.handle.net/10316.2/32762

DOI:

DOI:http://dx.doi.org/10.14195/0870-4112_7_15

Accessed : $\quad$ 26-Apr-2023 11:24:14

A navegação consulta e descarregamento dos títulos inseridos nas Bibliotecas Digitais UC Digitalis, UC Pombalina e UC Impactum, pressupõem a aceitação plena e sem reservas dos Termos e Condições de Uso destas Bibliotecas Digitais, disponíveis em https://digitalis.uc.pt/pt-pt/termos.

Conforme exposto nos referidos Termos e Condições de Uso, o descarregamento de títulos de acesso restrito requer uma licença válida de autorização devendo o utilizador aceder ao(s) documento(s) a partir de um endereço de IP da instituição detentora da supramencionada licença.

Ao utilizador é apenas permitido o descarregamento para uso pessoal, pelo que o emprego do(s) título(s) descarregado(s) para outro fim, designadamente comercial, carece de autorização do respetivo autor ou editor da obra.

Na medida em que todas as obras da UC Digitalis se encontram protegidas pelo Código do Direito de Autor e Direitos Conexos e demais legislação aplicável, toda a cópia, parcial ou total, deste documento, nos casos em que é legalmente admitida, deverá conter ou fazer-se acompanhar por este aviso.

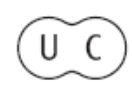




\section{Sociedade em Tumulto}

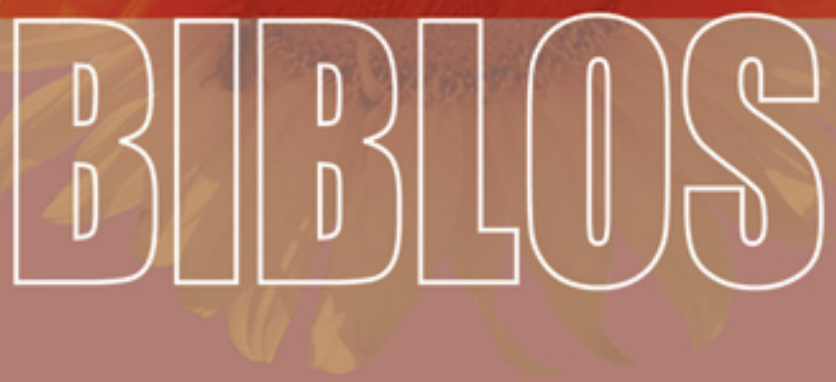

REVISTA DA FACULDADE DE LETRAS

UNIVERSIDADE DE GOIMBRA 
Biblos, n. s. VII (2009) 347-360

\author{
Rita Marnoto \\ Universidade de Coimbra
}

\title{
EUGÉNIO DE CASTRO ENTRE SIMBOLISMO E FUTURISMO
}

\section{Resumo}

Apesar de o nome de Eugénio de Castro andar associado à introdução do Simbolismo na literatura portuguesa, é referido por duas publicações periódicas que, de uma forma ou de outra, se encontram ligadas ao Futurismo. A primeira é Poesia (1906), a revista internacional editada por Marinetti, em Milão. A segunda é a Revista da Índia (1914), publicada por um grupo de escritores indo-portugueses, em Nova Goa. Daí resulta uma visão mais abrangente da obra de Eugénio de Castro e da sua dimensão internacional, bem como um melhor conhecimento das articulações do Futurismo, através de um percurso que, de Itália, se estende até à Índia, passando por Portugal e pelo Brasil.

Palavras-chave: Futurismo, Simbolismo, Eugénio de Castro, Filippo Tommaso Marinetti, Poesia, Revista da Índia

\section{Abstract}

Although Eugénio de Castro's name is generally associated with the introdution of Symbolism in Portuguese literature, he is quoted by two periodical publications that, in one way or another, are connected with Futurism. The first is Poesia (1906), an international review edited by Marinetti, in Milan. The second is Revista da Índia (1914), edited by a group of Indo-Portuguese writers, in New Goa. This gives us a broader view of Eugénio de Castro's work and of his international dimension, as well as a deeper knowledge of his connections with Futurism, through a trajectory that extends from Italy to India, and that includes Portugal and Brazil.

Keywords: Futurism, Symbolism, Eugénio de Castro, Filippo Tommaso Marinetti, Poesia, Revista da Índia.

Período de intensa agitação, os anos que correm entre os finais do século XIX e os inícios do século XX são marcados, também no plano literário, por uma complexa intersecção entre permanências e rupturas. 
As grandes mudanças que afectaram modos e estilos de vida, em particular pelo que diz respeito à aceleração das comunicações, muito contribuíram para a intensificação dos contactos entre intelectuais e escritores, assim estimulando o debate e o intercâmbio de ideias. Nesse âmbito, o Futurismo ocupa uma posição de destaque. Ao colocar no seu cerne a estética da máquina, elegendo a velocidade como emblema de um programa que faz do presente futuro, foi um dos movimentos que mais contribuiu para esse intercâmbio. Mas um tal dinamismo erige-se, da mesma feita, em factor não só da sua projecção internacional, como também da pluralidade das suas manifestações específicas, situação bem representada, aliás, no domínio português ${ }^{1}$.

É sobre este pano de fundo que melhor podemos compreender quanto de surpreendente fica contido na combinação de elementos literários, antropológicos e até geográficos, que envolve as referências a Eugénio de Castro incluídas em Poesia e Revista da Índia. A obra de um dos poetas que mais decisivamente contribuiu para a introdução do Simbolismo em Portugal faz-se assunto, pois, de duas revistas que, de uma forma ou de outra, se encontram ligadas ao Futurismo. A primeira delas, destacado órgão do projecto de Filippo Tommaso Marinetti, saiu em Milão. A segunda, de difusão circunscrita e de efémera duração, foi publicada na Índia colonial portuguesa, em Nova Goa.

Quanto à revista Poesia, a referência encontra-se numa carta de 1906 que o poeta brasileiro Carlos Magalhães de Azeredo dirigiu a Marinetti (Poesia, 3-4-5, 32-33), e que depois foi reeditada no volume Enquête internationale sur le vers libre et Manifeste du Futurisme par F. T. Marinetti (Milano, Éditions de Poesia 1909, 89-95)². Quanto à Revista da Índia, trata-se da rubrica intitulada "A carvão", que no número de Janeiro de 1914 é dedicada a "Eugénio de Castro" por Adolfo Costa (Revista da Índia, 1 7, 103-104).

Para ilustrar a projecção internacional do poeta, bastará recordar a célebre entrevista dada a António Ferro por Gabriele D’Annunzio, em Fiume, no mês de Novembro de 1920. Depois de uma troca de ideias preliminar, é o entrevistado quem interroga o entrevistador, para

${ }^{1}$ Desenvolvi o assunto em 'Futurismo e Futurismos em Portugal', Estudos Italianos em Portugal n.s. 4 (2009) 61-75.

${ }^{2}$ Silvio Castro, em 'Carlos Magalhães de Azeredo e a Enquête internationale sur le vers libre de Marinetti', in Giovanni Battista De Cesare / Silvana Serafin (eds.) El girador. Studi di letterature iberiche e ibero-americane offerti a Giuseppe Bellini (Roma, Bulzoni 1993) vol. 1 191-199, transcreveu e analisou globalmente essa intervenção. 
lhe pedir notícias acerca de Eugénio de Castro, que considera um dos maiores simbolistas ${ }^{3}$ :

Portugal, eu sei, é um país de poetas. Nascem, vivem, morrem - como flores... Que é feito de Eugénio de Castro? Vive ainda? É um grande poeta, um dos maiores simbolistas que tenho conhecido.

Eugénio de Castro (Coimbra, 1869-1944) foi, indubitavelmente, um dos poetas portugueses do seu tempo com maior renome no estrangeiro ${ }^{4}$. Depois de ter concluído o Curso Superior de Letras em Lisboa, partiu para um tour europeu que o levou até Paris, talvez na perspectiva da carreira diplomática que veio a seguir até 1894. Essa viagem deu-lhe ensejo de conhecer de perto o movimento simbolista, na sua génese e nos seus desenvolvimentos, e, além disso, de contactar com alguns dos seus maiores representantes. Regressado a Portugal em 1889, foi pioneiro na divulgação da obra de Laforgue, Kahn, Ghil ou de Régnier, mantendo uma ampla rede de contactos europeus. A revista Arte, que tinha por subtítulo Revista Internacional, foi destacado veículo desse cosmopolitismo. Fundou-a em Coimbra, juntamente com Manuel da Silva Gaio, dela tendo saído oito números, entre 1895 e 1896.

As relações com a intelectualidade europeia, por sua vez, serão uma constante ao longo do seu percurso intelectual. Cartas, sinais de apreço mútuo, traduções de autores estrangeiros ou traduções da sua própria obra para outras línguas sugerem uma rede de contactos dotada de um vasto impacto internacional, cujos contornos mereceriam ser mais profundamente estudados. Em 1914, passa a Professor da Faculdade de Letras da Universidade de Coimbra, onde trabalha em prol do desen-

${ }^{3}$ António Ferro, Gabriele D’Annunzio e eu (Lisboa, Portugália 1922) 57.

${ }^{4}$ Sobre as suas relações com a Itália, país onde foi reiteradamente traduzido, vd. Sabina Gola, 'Notes sur Eugénio de Castro et l'Italie', Jean Marie d'Heur / René Poupart (eds.) Centenário da publicação de "Oaristos" de Eugénio de Castro (Paris, FCG 1999) 87-100. Quanto à França, vd. Pierre Rivas, 'Eugénio de Castro en français: textes retrouvés', Nova Renascença 9 35-38 (1990) 169-177. Quanto à Espanha, vd. os aparatos que acompanham a edição das Obras poéticas de Eugénio de Castro (reprodução fac-similada dirigida por Vera Vouga, Porto, Campo das Letras 2001-2007) 3 vols. Para uma perspectiva global do pensamento de Eugénio de Castro, vd., mais recentemente, Paulo Archer, 'Cartas de António Sardinha para Eugénio de Castro (1905-1924)', Arquivo Coimbrão. Boletim da Biblioteca Municipal, 40 (2008) 7-91. 
volvimento dos estudos franceses, dos estudos espanhóis e dos estudos italianos. Quando, em 1927, é fundada a Sala Italiana da Faculdade de Letras, Eugénio de Castro, que manteve, ao longo dos tempos, relações de proximidade com a Itália, foi o seu primeiro Director ${ }^{5}$.

Os prefácios que acompanham as suas primeiras recolhas de poesia, nomeadamente a primeira e a segunda edições de Oaristos e Horas, exprimem, de modo palmar, os princípios que sustêm a sua poética simbolista. A segunda edição de Oaristos, de 1900, faz-se ocasião para um balanço crítico acerca das inovações introduzidas, ao qual se segue uma síntese do seu teor ${ }^{6}$ :

Há neste volume uma forte dose de exagero, que muitos atribuíram a um juvenil desejo de épâter le bourgeois, mas que, rigorosamente, deve ser explicada pela necessidade de sublinhar com um violento traço vermelho a estagnada vulgaridade das formas poéticas de então.

O efeito da minha tentativa excedeu em amplitude e rapidez os cálculos que eu próprio tinha deitado. Quase todos os meus camaradas, novos e velhos, alguns no galarim, tomaram pelo caminho que eu desbravara. A mobilização da cesura nos alexandrinos e a dos acentos clássicos no decassílabo, o esmero no emprego das rimas, a escolha rigorosa dos epítetos, o alargamento do vocabulário, a restauração dos moldes arcaicos, o verso livre, a aliteração: - todas essas inovações, iniciadas nos Oaristos e continuadas depois nas Horas, são hoje formas correntes na poética nacional, que, evidentemente, saiu, por via delas, da paralisia que a entrevava.

Arma primordial no combate a essa paralisia que entrevava as letras portuguesas, é, para Eugénio de Castro, a abertura ao plano europeu, como se inovação literária e intercâmbio intelectual fossem duas faces de uma mesma moeda. Por um lado, a amplitude desse horizonte inter-

${ }^{5}$ Vd. Rita Marnoto, 'O ensino da língua e da literatura italianas na Universidade de Coimbra', in Maria Hermínia Amado Laurel (ed.), Para uma história das línguas e literaturas estrangeiras em Portugal. Das origens à actualidade (Aveiro, Aphelle 2001) 91-117; e Jorge Pais de Sousa, Uma biblioteca fascista em Portugal (Coimbra, Imprensa da Universidade 2007).

${ }^{6}$ Prefácio à segunda edição de Oaristos, Eugénio de Castro, Obras poéticas vol. 1 13-14 (1. ${ }^{a}$ ed., Coimbra, Tipografia de Manuel Caetano da Silva, Livraria de Manuel de Almeida Cabral 1890; 2. ${ }^{a}$ ed., Coimbra, França Amado 1900). Todos os textos são transcritos com fixação.

Faculdade de Letras | Universidade de Coimbra 
nacional erige-se em factor vital da sua adesão ao Simbolismo. Por outro lado, dinamiza um sistema de contactos que corrobora a recepção dessas inovações.

O prefácio foi escrito em 1900, o que remete para o sentido da evolução da obra de Eugénio de Castro. Se esse percurso é complexo, a imbricação de tendências que, a partir de um certo ponto, o atravessam, torna muito difícil uma sistematização absoluta. Pela forma como, esporadicamente, se dedica à versificação, Óscar Lopes designou-o como um novo Castilho $^{7}$, ao passo que José Carlos Seabra Pereira mostrou como a distinção entre Simbolismo e involução clássica, em Eugénio de Castro, não é, de modo algum, linear, também pela forma como se articula com o academismo e com o Neo-Romantismo ${ }^{8}$.

Esta adesão ao Simbolismo, num contexto internacional, e em diálogo com o classicismo de formas e temas, são importantes chaves para a interpretação dos comentários que ficam contidos em Poesia e na Revista da Índia.

Mas, para além disso, numa época em que os vários -ismos se sucedem e se interpenetram ao ritmo da vida moderna, há que ter em linha de conta a própria génese do Futurismo, na complexidade dos elos de ligação que se estabelecem entre o movimento de vanguarda liderado por Marinetti e o Simbolismo. O assunto foi estudado por vários $\operatorname{críticos}^{9}$, que são consensuais no reconhecimento da inter-relação entre Simbolismo e Futurismo, ao longo de toda aquela primeira fase da actividade de Filippo Tommaso Marinetti que costuma ser designada como pré-futurista ${ }^{10}$.

7 'Decadentismo e Simbolismo. Eugénio de Castro e a sua evolução classicizante', Entre Fialho e Nemésio. Estudos de literatura portuguesa contemporânea (Lisboa, INCM 1987) 106.

8 'No centenário de Oaristos', Colóquio Letras 68-88 113-114 (1990) 68-88.

${ }^{9}$ Com relevo para Bruno Romani, Simbolismo e Futurismo (Firenze, Remo Sandron 1969); Gaetano Mariani, Il primo Marinetti (Firenze, Le Monnier 1970); Brunella Eruli, 'Preistoria francese del Futurismo', Rivista di Letterature Moderne e Comparate 234 (1970) 245-290; e sem esquecer Marcel Raymond, apesar de as alusões a Marinetti e ao Futurismo contidas em De Baudelaire au Surréalisme. Essai sur le mouvement poétique contemporain (Paris, R.-A. Corrêa 1933) serem fugazes.

${ }^{10} \mathrm{Cf}$. Giusi Baldissone, que na monografia que dedica ao líder do Futurismo, recentemente reeditada (Filippo Tommaso Marinetti Milano, Mursia 2008), com referência a esta fase de gestação, reafirma o epíteto de "Marinetti prefuturista", título do segundo capítulo. 
Na verdade, se o Manifesto de fundação do Futurismo foi publicado em Le Figaro de 20 de Fevereiro de 1909 e, simultaneamente, em folha volante, a gestação do conjunto de propósitos que o sustém começa muito antes ${ }^{11}$. Filho de um advogado que emigrou para o Egipto, Marinetti é educado em Alexandria, no colégio jesuíta francês de São Francisco Xavier, partindo para a Europa em 1893. Obtém então o baccalauréat ès lettres em Paris e estuda nas Universidades de Pavia e de Génova. Move-se, já nessa altura, por entre uma rede de relações literárias e intelectuais muito ampla, que do roteiro Paris-Milão se estende aos Países Baixos. Em 1898, ganha um prémio nos Samedis populaires de Catulle Mendès e Gustave Kahn, com o poema em verso livre Les vieux marins, que é recitado por Sarah Bernardt. Publica versos nas revistas francesas $L a$ Plume, La Revue Blanche, La Rénovation Esthétique, La Vogue, Vers et Prose, todas elas destacados arautos da poesia simbolista. Dedica-se, em particular, à revista ítalo-francesa Anthologie Revue de France et d'Italie, da qual foi secretário para a Itália. Entretanto, vai participando em espectáculos e recitais de poesia, até que, em 1905, funda a revista Poesia, em Milão.

Os poemas de Marinetti escritos durante este período carregam em si os sinais da ruptura que está prestes a consumar-se. Tratam temas característicos da estética simbolista, relacionados com a sensualidade, a natureza agitada ou o mundo do além, aos quais se associa, muito frequentemente, a impossibilidade de alcançar um absoluto. Do confronto entre o anseio de atingir novos horizontes e novas modalidades de expressão, e os respectivos impedimentos, resulta o desprezo da razão e uma agressividade que prenuncia a eleição da guerra como valor essencial do Futurismo. Em termos literários, daí decorre a negação daquelas facetas do Simbolismo de cariz mais tradicional, ou até ligadas a moldes classicizantes, as quais acabam por se esgotar, em prol da ligação à vida moderna. Concomitantemente, os ritmos do verso livre de Gustave Kahn vão-se enchendo de cadências sucessivamente mais marcadas. Levada até às suas últimas consequências, esta posição desemboca na condenação da própria poesia, considerada motivo de esterilidade criativa. É significativo que, nos versos do Marinetti pré-futurista, as imagens se espalhem por toda a página, de modo profuso e imediato, assim abrindo caminho àquela rede de imagens e analogias, proclamada no Manifesto técnico da literatura futurista, de 1912,

\footnotetext{
${ }^{11} \mathrm{Na}$ realidade, já anteriormente circulara em Itália. Dei informações actualizadas sobre esta questão no já citado 'Futurismo e Futurismos em Portugal', 61-62. 
resultante da supressão do primeiro termo comparativo. A este propósito, tem vindo a ser reiteradamente recordado o precedente de Alfred Jarry, pelo modo como tendia a fazer da imagem objecto. Numa radicalização de posições, é breve o passo que vai da descrença na mediação psicológica e na razão, até à abolição da sintaxe; ou da hostilização da subjectividade, até à supressão do adjectivo e do advérbio, em prol do golpe de intuição. Ao desgaste do significado lógico-expressivo daí decorrente, sobrepõe-se a exploração do plano fonético e da visualidade do texto.

A ligação ao Simbolismo e ao Decadentismo é bem ilustrada, além disso, pelo espaço que a revista Poesia reserva a Giosuè Carducci, a quem é dedicada, a Giovanni Pascoli e a Gabriele D’Annunzio. Essa proximidade logo se desdobra, porém, em paradoxo, tendo em linha de conta a veemência com que Marinetti, em Les dieux s'en vont D'Annunzio reste, de 1908, ataca D'Annunzio. Na base do conflito, encontra-se, afinal, uma disputa em torno de um ideal comum. O refinado poeta de gosto iconoclasta reivindicava, também ele, um lugar, na criação do movimento de vanguarda.

A revista Poesia é fiel espelho desta encruzilhada de sentidos ${ }^{12}$. A sua publicação iniciou-se no mês de Fevereiro de 1905, em Milão, e estendeu-se até 1909, com regularidade mensal, num total de 31 fascículos. Em 1906, a direcção passou a ser assumida unicamente por Marinetti, que financiava o empreendimento. De entre as iniciativas e rubricas de maior impacto, contam-se os inquéritos, com relevo para o inquérito sobre o verso livre, cujas respostas foram posteriormente coligidas em volume autónomo. Mas não se esqueçam outros inquéritos que suscitaram, igualmente, grande interesse, como seja o que foi dedicado à beleza da mulher italiana. As notas monográficas sobre poetas considerados de relevo mostram muito bem a dimensão internacional desta publicação: Gustave Kahn, Francis Vielé-Griffin, Stuart Mellin, Henri de Régnier, Francis Jammes, Paul Fort, Alfred Jarry; membros do grupo da Abbaye, como Charles Vildrac, Alexandre Mercereau, Georges Duhamel; fantasistas, neo-simbolistas, parnasianos, adeptos da École Romaine, do Naturismo ou do Unanimismo. Quanto à produção em verso, além de poetas italianos e de língua francesa, são publicados ingleses e irlandeses

${ }^{12}$ Remetemos para os aparatos de Giorgio Baroni e Federica Millefiorini que acompanham a edição facsimilada, Poesia. Rassegna Internazionale diretta da Filippo Tommaso Marinetti, Sem Benelli, Vitaliano Ponti (Pisa, Roma, Istituti Editoriali e Poligrafici Internazionali 20055 vols.). 
(Keats, Yeats), gregos, turcos, russos, espanhóis, latino-americanos e também, por entre tantos outros, poetas de língua portuguesa.

O referido inquérito sobre o verso livre, levado a cabo entre 1905 e 1907, ilustra bem o interesse de Marinetti por essa modalidade de versificação, sendo Gustave Kahn um dos inquiridos. Mas, além disso, faz-se ocasião para um balanço crítico acerca do panorama literário contemporâneo. De entre os participantes, contam-se os nomes de muitos outros grandes protagonistas da renovação em curso, no plano internacional (Verhaeren, Griffin, de Régnier, a Condessa de Noailles, Ada Negri, Dehmel, Pascoli, Colautti, D’Annunzio, Lucini, Buzzi, etc.). Pelo que diz respeito a Carlos Magalhães de Azeredo, o inquirido que cita Eugénio de Castro no seu depoimento, trata-se de um diplomata brasileiro que vivia em Roma, próximo de Machado de Assis, e também ele fundador da Academia Brasileira. Apesar de o seu nome, hoje, não ser muito conhecido, à data era um poeta com cinco livros publicados.

No seu depoimento, que é escrito em francês, Carlos Magalhães de Azeredo começa por se situar no plano da poética do verso livre, para depois passar ao da sua aplicação. Inicialmente, reconduz a questão ao ritmo, que elege lei universal, considerando-a tão importante como a lógica, ou até talvez mais ampla, real e íntima do que ela. Contudo, ao pronunciar-se acerca da prática dessa modalidade compositiva, num juízo que não é isento de notas forçadas, não deixa de lhe apontar aquelas fragilidades que, ao longo dos tempos, reiteradamente fizeram da poesia moderna um alvo fácil. Em seu entender, a ausência de regras ou esquemas métricos fixos presta-se ao encobrimento, sous le voile factice de la modernité, de um vazio de imaginação, através do mero decalque e do seguidismo. A apologia da regularidade métrica e da simetria mostra bem em que medida a poesia simbolista continuou a pagar o seu tributo aos modelos clássicos, o que é bem exemplificado pelos louvores que lhe merece a métrica regular da Commedia e de Os Lusíadas.

O périplo crítico descrito por Magalhães de Azeredo, entre as reservas que coloca às liberdades métricas do verso livre, o apreço pelas formas fixas e a tirania do alexandrino, tal como é usado em França, ganha sentido em função do orgulho com que expõe as suas opções pessoais ${ }^{13}$. É com ufania que se declara o introdutor, na literatura por-

${ }^{13}$ Silvio Castro já notou os limites desta perspectiva: "Evidentemente o poeta Magalhães de Azeredo não observara devidamente o percurso que o verso português há tempo realizava para uma modernidade que depois se mostraria derivada de João de Deus, passando por Cesário Verde e António Nobre, para chegar a poetas como Camilo 
tuguesa e na literatura brasileira, dos metros bárbaros, à maneira de Carducci. Ao mesmo tempo que lamenta que uma tal inovação não tenha sido aceite no vieux Portugal traditionnaliste, qui depuis quelques années se trouve plongé en une sorte de stagnation littéraire presque complète, regozija-se com o acolhimento que mereceu no Brasil, pays plus jeune, plus vibrant et moins misonéiste.

Como tal, através desse percurso, na sua resposta ao inquérito acaba por proceder a uma deslocação, da questão do verso livre, para a da métrica bárbara. Recorde-se, a esse propósito, que as tentativas de adaptar os modelos da métrica grega e latina às línguas modernas remontam, em Itália, aos primórdios do Renascimento. Nesse sentido, ora se optou por uma métrica baseada na quantidade de sílabas consideradas longas e breves, ora se enveredou pela exploração do ritmo, através da agregação de versos, na tentativa de imitar estrofes sáficas e alcaicas. Giosuè Carducci introduziu, nesse campo, grandes inovações. Criou uma estrutura que mimava dois tipos de verso da métrica latina, o hexâmetro e o pentâmetro, através da combinação de dois segmentos com medida métrica diferente. Chamou-lhe barbara, em conformidade com o título das suas mais que célebres Odi barbare, na convicção de que a sua proposta mais não era do que uma tentativa de aproximação da métrica clássica, tendo em linha de conta que de forma alguma seria possível superar, por essência, a condição histórica de qualquer autor de poesia. A desmontagem de formas e metros levada a cabo por Carducci, através de uma operação em que tecnicismo, mestria e fineza se equivalem, deu um fundamental contributo para a pesquisa em torno de esquemas sujeitos a novas modalidades de codificação. Ao mesmo tempo que, com as suas inovadoras propostas de estruturação métrica, mostrava caminhos a explorar, reconduzia essa pesquisa ao cariz normativo de uma preceituação basicamente clássica.

É depois dessas considerações acerca do papel que Carlos Magalhães de Azeredo entende ter desempenhado, enquanto introdutor da métrica bárbara, que, quando a sua resposta já se aproxima do fim, cita Eugénio de Castro:

Pessanha. Mas ele revela de haver saltado também e sem sentir nenhuma perda lições brasileiras como as de Sousândrade, Cruz e Sousa, etc., fato que o impedia de perceber que poetas como Emiliano Perneta, Mário Pederneiras, Augusto dos Anjos se estavam preparando em um tempo nacional contemporâneo ao seu para renovar a estrutura da poesia do Brasil", cit. 198.

Faculdade de Letras | Universidade de Coimbra 
En résumé, je pense que le vers libre, dans toute la hardiesse de son indépendance, dans toute la rigueur de sa signification technique, n'est pas appelé à avoir un grand avenir dans la Poésie portugaise; peutêtre deviendra-t-il l'instrument d'expression préféré de quelque illustre poète isolé, mais ne sera probablement jamais une forme littéraire courante. Importé pour la première fois en Portugal, il y a une quinzaine d'années, par un groupe de poètes hardis, qui avaient à leur tête Eugénio de Castro, dont le nom ne vous est peut-être pas inconnu, il n'a pu transpirer en dehors des limites restreintes d'un cénacle de jeunes, le public littéraire n'ayant voulu y voir qu'une imitation artificielle et purement académique dépourvue de toutes racines dans la tradition nationale.

(Enquête 94)

Por conseguinte, a resposta de Magalhães Azeredo ao inquérito sobre o verso livre conflui na enfatização da ousadia de Eugénio de Castro, a qual logo é avaliada, porém, com distanciamento. É subestimada a vertente europeísta do modelo importado pelo poeta português. Se as reservas que anteriormente colocara ao verso livre eram muitas e de fundo, no passo transcrito faz sua, em certa medida, a escassa simpatia que essa modalidade métrica mereceu a grande parte do público, parecendo não se dar conta da contradição em que cai. Esse grande público fora anteriormente identificado, afinal, como um vieux Portugal traditionnaliste, qui depuis quelques années se trouve plongé en une sorte de stagnation littéraire presque complète. Apresenta, pois, a inovação de Eugénio de Castro não só enquanto fenómeno isolado das letras portuguesas, que não envolve mais do que um círculo restrito de poetas por ele liderado, mas também enquanto imitação artificial e puramente académica.

Além disso, o esquematismo de uma tal posição deixa na sombra o quadro histórico da literatura portuguesa compreendido entre finais do século XIX e inícios do século XX. Como é sabido, o percurso que conduzirá à Modernidade antevê-se já em João de Deus, para depois levar por Cesário Verde, António Nobre, Camilo Pessanha ou mesmo Raul Brandão, até aos poetas de Orpheu ${ }^{14}$.

Carlos Magalhães de Azeredo move-se, pois, em duas frentes que funcionam como vasos comunicantes. Por um lado, menospreza

\footnotetext{
${ }^{14}$ Valha por todas a remissão para Fernando Guimarães, Simbolismo, Modernismo e vanguardas (Lisboa, IN-CM 2004 3. ${ }^{\mathrm{a}}$ ed.). 
o verso livre, em função do seu facilitismo. Por outro lado, valoriza a métrica bárbara, por cuja introdução, nas literaturas de língua portuguesa, entende ser responsável. Daqui decorre a parca importância que dispensa aos cultores do verso livre na literatura portuguesa, dos quais detém, aliás, um conhecimento parcial. Reconduz, pois, o valor de Eugénio de Castro para a escassa aceitação que mereceu do público e para o carácter circunscrito dessa experiência literária.

O poeta brasileiro que Filippo Tommaso Marinetti convida a responder ao seu inquérito não é, propriamente, um vanguardista. Gera-se, então, um efeito perspéctico donde resulta o engrandecimento do vanguardismo de Eugénio de Castro.

É de índole algo diversa a imagem apresentada pela Revista da Índia. Mas vejamos, entretanto, como surge este periódico.

Trata-se de uma publicação feita em Nova Goa, com o subtítulo de Mensal de Letras e Artes, que saiu entre Junho de 1913 e Julho de 1914, tendo por directores Paulino Dias e Adolfo Costa, que é o próprio autor da rubrica sobre Eugénio de Castro. A ligação ao Futurismo fica patente no primeiro número, que se abre com um denominado "Manifesto", no qual Marinetti ocupa um papel de relevo ${ }^{15}$.

O movimento de afirmação da Índia portuguesa que se forma entre finais do século XIX e inícios do século XX faz do jornalismo e da literatura duas das suas grandes frentes ${ }^{16}$. Paulino Dias, bem como outros dos colaboradores na Revista da Índia, pertenciam a esse grupo de escritores e jornalistas indo-portugueses. A produção poética coligida nos vários números, de grande interesse para a intersecção entre culturas e literaturas, caracteriza-se, como seria de esperar, por um acentuado pendor exótico, entre manifestações de índole simbolista, decadentista e neo-romântica, mas pouco ou nada tem de futurista. A vanguarda italiana era, porém, conhecida de modo próximo pelos colaboradores na revista, a ponto de, em 1913, no texto com que se inicia esta publicação periódica de Nova Goa, o Manifesto de fundação

${ }^{15}$ Vd. Sandra Bagno, 'Il Futurismo a Goa e la Revista da Índia', in Silvio Castro e Manuel Simões (eds.), Rosa dos Ventos. Atti del Convegno. Trenta anni di cultura di lingua portoghese a Padova e a Venezia (Padova, Università di Padova, Sezione Portoghese dell'Istituto di Lingue e Letterature Romanze 1994) 89-101; e 'O Futurismo libertário na Índia portuguesa', Jornal de Letras, Artes e Ideias 15640 (1995) 26-27, que dele transcreve largos passos.

${ }^{16}$ Vd. Vimalda Devi, Manuel de Seabra, A literatura indo-portuguesa (Lisboa, Junta de Investigação do Ultramar 1971) 2 vols.

Faculdade de Letras | Universidade de Coimbra 
do Futurismo, de 1909, ser considerado facto pretérito: publicado anos atrás, escreve-se ${ }^{17}$.

Nesse texto de abertura, os princípios programáticos da revista, ao serem transferidos, do domínio do editorial, para o do "Manifesto", que é o seu título, enchem-se de um tom combativo. Paulino Dias, que o assina, no objectivo de exaltar a Renascença literária das nacionalidades, toma Marinetti como baluarte da sua argumentação lógica. Ponto capital, é a energia de boxer com que o líder da vanguarda italiana combate o passadismo de um país antigo, o que mostra que as nações modernas são francamente futuristas. Depois de passar em resenha aspectos identitários, tipificados, de vários países, detém-se sobre a especificidade da Índia portuguesa, enquanto possível cruzamento entre Oriente e Ocidente donde brota o peito moço da Índia. Em seu entender, também o movimento de consciência nacional que aí se está a formar é uma reacção contra as forças atávicas e o misticismo absurdo.

É este o enquadramento futurista da revista de Nova Goa onde, em Janeiro de 1914, Adolfo Costa publica uma rubrica sobre Eugénio de Castro. O fio discursivo do texto nem sempre é claramente perceptível, e o conhecimento aproximativo de vários aspectos da obra do poeta não corrobora a limpidez de ideias.

Esta questão envolve várias outras questões de geografia literária. Uma revista indo-portuguesa de Nova Goa, em 1913, considera que o Manifesto de fundação do Futurismo, de 1909, fora publicado anos atrás. Contudo, em 1914, o livro de poemas de Eugénio de Castro A sombra do quadrante, efectivamente editado em $1906^{18}$, é referenciado como tendo saído à luz da publicidade no ano passado, e $O$ anel de Policrates, de $1896^{19}$, é apresentado como se estivesse no prelo. O que parece mostrar que os horizontes da Revista da Índia se encontram mais próximos de Itália do que de Coimbra.

Adolfo Costa começa por se referir a Eugénio de Castro como o insigne e original poeta de "Oaristos", apresentando-o enquanto iniciador do Simbolismo em Portugal. Oaristos é considerado numa

${ }^{17} \mathrm{O}$ poeta indo-português António Nascimento Mendonça publicara, no número de 1908-1909 de Poesia, uma composição dedicada a Marineti, o que mostra que existiam relações entre a vanguarda italiana e a vanguarda goesa que muito importaria estudar.

${ }^{18}$ Coimbra, França Amado 1906.

${ }^{19}$ Coimbra, Francisco França Amado 1896. 
dupla vertente, que diz respeito quer ao seu pioneirismo, quer às reacções que suscitou. Por um lado, o seu autor é superlativizado, em relação a outros poetas de finais do século XIX e inícios do século XX, como sejam João de Deus, Soares de Passos, Tomás Ribeiro, António Nobre e Cesário Verde. Por outro lado, recordam-se as reservas de João de Deus e a paródia de João Saraiva.

Contudo, quanto à produção sucessiva, não são poupadas críticas. Esses reparos decorrem de uma trajectória que, no entender do articulista, se orientou em função de cedências ao gosto do público. Adolfo Costa manifesta-se abertamente reactivo, relativamente àquele que parece considerar ser o seu último livro, A sombra do quadrante. A rapidez com que se deu a transformação do estilo explica as lacunas e os defeitos primaciais dessa obra, ao longo de cujas páginas é à força de arte que ele nos dá uma grande impressão de sentimento. Nas suas páginas, revela-se mais artista que sentimental, guiado por uma musa feita cortesã dengosa e conhecedora da etiqueta, fazendo cintilar com uma arte infinita as suas pedrarias falsas e trazendo no olhar um brilho enganoso que fascina e seduz, mas que não tem coração. Por isso, a terminar, deseja que o poeta, deixando os novos moldes do nefelibatismo ${ }^{20}$, abrace de vez a forma clássica, a única que realiza certamente o verdadeiro ideal da verdadeira Arte.

À semelhança do que se passa com Carlos Magalhães de Azeredo, Adolfo Costa não deixa de proceder a uma simplificação do quadro evolutivo da literatura portuguesa da época. No entanto, coloca-se numa óptica substancialmente diferenciada da do inquirido brasileiro, a quem o verso livre do poeta de Oaristos parecia demasiado ousado. O anseio de que Eugénio de Castro abrace de vez a forma clássica, expresso no final do artigo, só aparentemente poderá parecer paradoxal. Na verdade, para o articulista, tanto as inovações de Oaristos e de Horas, como um desejável regresso à forma, são estações de um mesmo percurso, afinadas por uma mesma exigência de rigor na construção de versos que suscitam efeitos emocionais. À exaltação de Oaristos, no início

${ }^{20}$ Provável alusão ao conceito explanado no prefácio de Horas, obra que começa por designar como "silva esotérica para os raros apenas": "Tal a obra que o poeta concebeu longe dos bárbaros, cujos inscientes apupos, - al não é de esperar, - não lograrão desviá-lo do seu nobre e altivo desdém de nefelibata”. A recolha teve a primeira edição em Coimbra, Tipografia de Manuel Carneiro da Silva, Manuel de Almeida Cabral Editor, 1891 (cit. de Obras poéticas, vol. 193-94) e a segunda também em Coimbra, Francisco França Amado, 1912. 
do artigo, corresponde o desejo de que abandone os novos moldes do nefelibatismo.

A evolução de Eugénio de Castro que se espera vai no sentido do regresso aos moldes de um Simbolismo que o articulista parece aproximar do classicismo. Um classicismo que tanto poderá ser entendido como uma permanência, no âmbito da trajectória do poeta, um velho nefelibatismo, dir-se-ia, ou como expressão do apreço merecido por aqueles aspectos da poética simbolista que condensam uma arte pura, alheia a pedrarias falsas.

Daqui resulta que, aquilo que (ou parte daquilo que) Carlos Magalhães de Azeredo não aprecia na obra de Eugénio de Castro, o verso livre, corresponda, em termos aproximativos, ao que Adolfo Costa dela valoriza. E, no entanto, Azeredo publica a sua opinião na revista de Marinetti, a seu convite, e vê-a reeditada em volume, ao passo que Adolfo Costa escreve da Índia portuguesa, nas páginas de uma revista que se abre com o nome do líder do movimento italiano.

$\mathrm{Na}$ sua fluidez e nas suas contradições, ambas as opiniões manejam tópicos que circulavam de forma recorrente naquela zona de fronteira entre Simbolismo e Futurismo, como a questão dos modelos métricos ou a relação entre formalismo e emotividade poética. Na verdade, foi nessa ala avançada do Simbolismo que germinaram muitos dos propósitos da ruptura futurista.

Os assuntos debatidos continuam a concentrar a atenção das pesquisas que têm vindo a ser realizadas quer em torno do Simbolismo, quer em torno da obra de Eugénio de Castro, com relevo para as questões suscitadas, ainda hoje, pela evolução do seu percurso literário. Mas, além disso, os juízos críticos analisados traçam uma imagem de Eugénio de Castro lançada a partir de um novo ângulo. À vasta rede de relações que liga o poeta a intelectuais e escritores da mais diversa proveniência, acrescenta-se, pois, uma nova tessela, entre Simbolismo e Futurismo. 